\title{
Influence of Natural Honey on Biochemical and Hematological Variables in AIDS: A case study
}

\author{
Noori S. Al-Waili, Thia N. Al-Waili, Ali N. Al-Waili, and Khelod S. Saloom \\ Al-Waili's Charitable Foundation for Research and Trading, New York, USA, and Dubai Specialized \\ Medical Center, Islamic Establishment for Education, UAE. \\ E-mail: noori786@yahoo.com
}

Received September 14, 2005; Revised October 11, 2005; Accepted October 14, 2005; Published February 2, 2006

Honey lowers prostaglandins and elevates nitric oxide (NO) in various biological fluids in normal persons. NO and prostaglandin play a role in pathogenesis of AIDS. The study was designed to assess the effect of natural honey on prostaglandins and NO levels, blood indices and biochemical tests in a 40 year-old woman with AIDS. This presentation is a case story of a 40 year-old women with a long history of AIDS treated with $80 \mathrm{~g}$ of natural honey. Plasma and urinary prostaglandin F2 alpha and thromboxane B2 levels, plasma, urine and saliva content of NO-end product (total nitrite) and hematological tests were estimated before and 3 hours after oral consumption of $80 \mathrm{~g}$ of natural honey. These variables, in addition to biochemical tests, were re-estimated after 21 days of daily consumption of $80 \mathrm{~g}$ of natural honey. Results showed that prostaglandins level compared with normal subjects were elevated in patient with AIDS. Natural honey decreased prostaglandins levels, and elevated NO-end product, percentage of lymphocytes, platelet count, and serum protein, albumin and copper levels. It might be concluded that natural honey decreased prostaglandins level, elevated NO production and improved hematological and biochemical tests in a patient with a long history of AIDS.

KEY WORDS: AIDS, honey, nitric oxide, prostaglandin, blood indices, blood biochemistry, United States

\section{INTRODUCTION}

Many reports have shown that honey has wide biological and therapeutic effects. It has been used for a long time to treat wounds and burns. It was mentioned in the Holy Quran as a cure for all illnesses (And thy LORD taught the bee to build its cells in hills, on tree and in men's habitations, then to eat of all the produce of the earth and find with skill the spacious paths of its LORD, there issues from within their bodies a drink of varying colors, wherein is healing for men, verily in this is a sign for those who give thought. Surat Al-Nahl (The Bees), Aya 69). Honey has been used for treatment of respiratory diseases, urinary diseases, gastrointestinal diseases, and skin diseases including ulcers, wounds, eczema, psoriasis and dandruff[1,2,3]. It has an excellent antibacterial activity against a wide range of human pathogens[4,5]. Recently, we have found that topical honey application is useful for treatment of recurrent herpetic lesions[6]. Honey stimulated proliferation of B and T lymphocytes in cell culture and stimulated 
monocytes to release cytokines, which activated immune responses[7]. Recently we have found that various honeys contained different amount of nitric oxide (NO) metabolites and intravenous honey could increase urinary nitrite excretion in animals[8]. Oral honey ingestion increases plasma, saliva and urinary contents of NO metabolites[9]. In normal subjects, we found that honey could reduce plasma prostaglandin E2, prostaglandin F2 alpha and thromboxane B2 levels[10]. Urinary excretion of prostaglandins was reduced by honey[11]. In addition, two weeks consumption of honey by normal subjects increased concentration of antioxidants in the blood and slightly increased the percentage of lymphocytes, hemoglobin, red blood cell and platelet count[12]. A 33\% increase in the serum copper level was obtained[12].

The objective of this study was to find whether raw unprocessed honey could affect prostaglandin and NO production in a patient with a long history of AIDS.

\section{CASE REPORT}

A 40 year-old woman suffering from AIDS for 10 years was studied. She had HIV-1 infection since 1992. At time of entry, she complained of tiredness and anxiety. No other symptoms were found on systemic review. Physical examination revealed normal findings. The patient did not receive any antiviral therapy during the six months preceding the test. Hematological and biochemical investigations were performed after 16 hours of fasting. Plasma and urinary PGF2 alpha and thromboxane B2 were estimated using the quantitative analysis performed with use of an enzyme linked immunosorbant assay (ELISA, Neogen Corporation, USA). Total nitrite (stable NO end product) was estimated in plasma, urine and saliva using Griess Reagent (Assay Designs, USA). Prostaglandins and total nitrite were estimated after 16 hours of fasting. Then the patient was asked to intake $80 \mathrm{~g}$ of natural honey (Multifloral). After 3 hours, estimation of blood indices, prostaglandins and total nitrite was repeated. The patient was asked to intake $80 \mathrm{~g}$ of natural honey once daily for a maximum of 21 days. On day 22, total nitrite was estimated in the urine, saliva and plasma samples and prostaglandins were estimated in plasma and urine samples. Hematological and biochemical tests were repeated on day 22 after honey intake. Results showed that total nitrite was increased in plasma and saliva after 3 hours and after 21 days (Table 1). The urinary nitrite level was increased from $30.7 \mu \mathrm{mol} / \mathrm{L}$ before honey intake to $56 \mu \mathrm{mol} / \mathrm{L}$ after 21 days of honey intake. Prostaglandin F2 alpha and thromoboxane B2 levels were decreased after 3 hours and after 21 days in plasma and urine samples. Platelet count and percentage of lymphocytes were increased 3 hours after honey intake and after 21 days (Table 1). Biochemical tests repeated after 21 days of treatment showed that there was an increase in serum protein from $6.8 \mathrm{~g} / \mathrm{dl}$ to $7.2 \mathrm{~g} / \mathrm{dl}$, serum albumin from $4 \mathrm{~g} / \mathrm{dl}$ to $4.5 \mathrm{~g} / \mathrm{dl}$, fasting blood sugar from $74 \mathrm{~g} / \mathrm{dl}$ to $85 \mathrm{~g} / \mathrm{dl}$, serum copper level from $97 \mathrm{mg} / \mathrm{dl}$ to $120 \mathrm{mg} / \mathrm{dl}$, uric acid from $2.3 \mathrm{mg} / \mathrm{dl}$ to $2.7 \mathrm{mg} / \mathrm{dl}$ and alkaline phosphates from $62 \mathrm{U} / \mathrm{L}$ to $94 \mathrm{U} / \mathrm{L}$. Gamma GT was decreased from $26 \mathrm{U} / \mathrm{L}$ to $12 \mathrm{U} / \mathrm{L}$ and SGPT from $12 \mathrm{U} / \mathrm{L}$ to $9 \mathrm{U} / \mathrm{L}$. It seems that natural honey could increase total nitrite level in the urine, plasma and saliva and decrease prostaglandins concentration in the urine and plasma. Honey also increased percentage of lymphocytes, serum protein, serum albumin and serum copper level.

\section{DISCUSSION}

The results showed that prostaglandins levels were elevated in a patient with AIDS. Natural honey reduced elevated prostaglandins levels and increased NO production, serum protein and albumin, platelet count, and percentage of lymphocytes. These changes might help patients with AIDS and ameliorate their health problems. Honey increases NO and reduces prostaglandins in various biological fluids[8-10]. It has been demonstrated that NO has an antiviral effect and there is some evidences of NO-activity decreasing or blocking HIV-1 replication[13]. NO-donors inactivate the HIV-1 encoded protease and reverse transcriptase[14]. NO is a very important mediator of immune responses[15]. Sera from person 
Table 1.

Effect on honey consumption (80 g/day) on nitric oxide-end product (nitrite), prostaglandins and blood indices in the patient with AIDS.

\begin{tabular}{lccc}
\hline Variables & \multicolumn{3}{c}{ Time after consumption } \\
\cline { 2 - 4 } & $\mathrm{O}$ & $3 \mathrm{~h}$ & 22 days \\
\hline & & & \\
Prostaglandin F2 alpha (plasma) ng/m1 & 1.30 & 0.23 & 0.12 \\
Prostaglandin F2 alpha (urine) ng/m1 & 2.25 & 0.99 & 2.2 \\
Thromboxane B2 (plasma) ng /m1 & 0.65 & 0.3 & 0.2 \\
Thromboxane B2 (urine) ng/m1 & 0.30 & 0.10 & 0.2 \\
Total Nitrite (plasma) $\mu \mathrm{mol} / \mathrm{L}$ & 18.9 & 34.82 & 73 \\
Total Nitrite (saliva) $\mu \mathrm{mol} / \mathrm{L}$ & 50.3 & 139.5 & 117 \\
White blood cell Count K/uL & 4.7 & 4.69 & 4.5 \\
Lymphocyte (\%) & 39 & 55 & 50 \\
Granulocyte (\%) & 55 & 36 & 45 \\
Monocyte (\%) & 5 & 7 & 5 \\
Eosinophil (\%) & 1 & 2 & 1 \\
Hemoglobin (g/d) & 11.8 & 11.8 & 11.9 \\
Platelet K/uL & 133 & 267 & 277 \\
\hline
\end{tabular}

with AIDS contain inhibitors of lymphocytes proliferation such as prostaglandin[16]. PGE2 produced by HIV-infected antigen presenting cells causes lymphocytes apoptosis[17]. Cyclooxygenase inhibitors blunted this effect[17]. In a murine model of AIDS, mice treated with prostaglandin inhibitor showed higher total leukocytes and platelet and higher helper cells[18]. Plasma prostaglandin F2 alpha and thromboxane B2 levels were found to be higher in the patient with AIDS as compared with normal subjects[10]. Natural honey decreased elevated plasma prostaglandin F2 alpha and thromboxane B2 to, or even below, the mean level of prostaglandin found in normal subjects[10]. In addition, natural honey decreased urinary prostaglandins concentration in a patient with AIDS. Plasma and saliva levels of total nitrite in the patient with AIDS were lower than those in normal subjects[9]. Natural honey increased NO end product in saliva, plasma and urine samples. However, high output of NO production may represent a potential risk to the human[15]. Nevertheless, honey did not provoke great increments in NO-end products. Twenty-three years ago, we had found that prostaglandin was a potent immunosuppressive and accordingly it had been suggested that inhibition of prostaglandin might increase immunity in conditions associated with the over production of prostaglandins such as chronic inflammations and malignancies[19]. Moreover, we have found that honey increased antibody production against thymus dependent and thymus independent antigens[20]. These honey's effects may help patients with AIDS.

Many Phase II, double-blind, placebo-controlled studies conducted on patients with AIDS showed various effects of placebo on the patient's health and parameters[21-25]. However, there has been vigorous debate over the use of placebo controls in clinical trials in human subjects where active treatments are already in widespread use, particularly the use of placebo controls in trials of products for AIDS[26]. In addition, there is ethical consideration for using placebo in certain conditions. In our case study, it was difficult to prepare placebo similar to honey. Furthermore, the patient knew that she was using honey as a nutrient. Nevertheless, the patient's care and handling from the medical staff might affect her condition. We suggest that further investigations, recruiting larger numbers of patients who 
consume natural honey for a longer period and who are compared with a control group using artificial honey (fructose and glucose), might substantiate the result of this observation.

\section{ACKNOWLEDGEMENTS}

The authors would like to thank Haj Saeed Lootah, Chairman of Trustee, Islamic Establishment for Education, Dubai, for his kind support. Mr Nader S. Boni provided assistance.

\section{REFERENCES}

1. Zaghloul, A., El-Shattawy, H., and Kassem, A. (2001) Honey, a prospective antibiotic: extraction, formulation, and stability. Pharmazie. 56, 643-647.

2. Al-Waili, N. (2003) Topical application of natural honey, beeswax and olive oil mixture for atopic dermatitis or psoriasis: partially controlled, single-blinded study.

Complement Ther Med. 11, 226-234.

3. Al-Waili, N. (2004) An alternative treatment for pityriasis versicolor, tinea cruris, tinea corporis and tinea faciei with topical application of honey, olive oil and beeswax mixture: an open pilot study. Complement Ther Med. 12, 45-47.

4. Al-Waili, N. (2004) Investigating the antimicrobial activity of natural honey and its effects on the pathogenic bacterial infections of surgical wounds and conjunctiva.

J Med Food. 7, 210-222.

5. Al-Waili, N., and Salom, K. (1999) Effects of topical honey on post-operative wound infections due to gram positive and gram negative bacteria following caesarean sections and hysterectomies. Eur J Med Res. 4, 126-130.

6. Al-,Waili, N. (2004) Topical honey application vs. acyclovir for the treatment of recurrent herpes simplex lesions. Med Sci Monit. 10, 94-98.

7. Aduharfeil, N., Al-Oran, R., and Abo-Shehada, M. (1999) The effects of bee honey on the proliferative activity of human B and T lymphocytes and activity of phagocytes. Food Agric Immunol, 11, 169-177.

8. Al-Waili, N. (2003) Identification of nitric oxide metabolites in various honeys and effects of honey on plasma and urinary nitrite/nitrate concentration. J Med Food. 6, 359-364.

9. Al-Waili, N. (2004) Honey increased saliva, plasma, and urine content of total nitrite concentrations in normal individuals. J Med Food. 7, 377-380.

10. Al-Waili, N., and Boni, N. (2003) Lowering effect of natural honey on plasma prostaglandins concentrations in normal nndividuals. J Med Food, 6, 129-133.

11 Al-Waili, N. (2005) Effects of honey on the urinary total nitrite and prostaglandin consumption. Int Urol Nephrol. 37,107-111.

12. Al-Waili, N. (2003) Effects of daily consumption of honey solution on hematological indices and blood minerals and enzymes levels in normal individuals. J Med Food, 6, 135-140.

13. Torre, D., Pugliese, A., and Speranza, F. (2002) Role of nitric oxide in HIV-1 infection: friend or foe? Lancet Infect Dis. 2, 273-280.

14. Persichinin, T., Ascenzi, P, and Colizzi, V. (1999) Molecualr bases for the anti-HIV- 1 effect of NO. Commentary. Int J Mol Med. 4, 365-368.

15. Zeidek, Z., and Masek, K. (1998) Erratic behavior of nitric oxide within the immune system: illustrative review of conflicting data and their immunopharmcological aspects. In J Immnuoharmcol. 20, 319-343.

16. Tomar, H., John, P., and Hinds, P. (1995) Reversal of immunosuppression of lymphocyte proliferation caused by sera from persons with AIDS. Clin Diag Lab Immunol. 2, 408-411.

17. Mastino, A., Gerlli, S., and Piacentini, M.. (1993) Correlation between induction of lymphocyte apoptosis and prostaglandin E2 production by macrophages infected with HIV. Cell Immunol. 155, 120-130.

18. Standler, I., Chadha, C., and Nakeeb, S. (1994) Pentoxifylline and meclofenamic acid treatment reduces clinical manifestations in murine model of AIDS. J Pharmacol Exp Ther. 26, 10-13.

19. Al-Waili, N., Thewani, A., and Al-Azzawi, H. (1980) The effects of PGA1 on antibody production. The World Conference on Clinical Pharmacology and Therapeutics. London, pp. 0246.

20. Al-Waili, N. (2004) Effects of honey on the primary and secondary immune responses due to thymus dependent and thymus independent antigens. J Med Food. 7, 491-494.

21. Flynn, N., Fortha, D., Harro, C., Judson, FN., Mayer, K. (2005) Para M. Placebo-controlled phase 3 trial of a recombinant glycoprotein 120 vaccine to prevent HIV-1 infection. $J$ Infect Dis. 191, 654-665.

22. Bourinbaiar, A., Jirathitikal, V., Metadilogkul, O., Sooksathan, P., Paiboon, P., Aemsri, S., Prapai, P., and Chaodon, K. (2004) Phase II placebo-controlled study of V-1 Immunitor as a therapeutic modality for treatment of HIV. J Clin Virol. 231 Suppl 1. S55-62.

23. Di Rocco, A., Werner, P., Bottiglieri, T., Godbold, J., Liu, M., Tagliati, M., Scarano, A., and Simpson, D. (2004) 
Treatment of AIDS-associated myelopathy with L-methionine: a placebo-controlled study. Neurology. 63,1270-1275.

24. Elliott, A., Luzze, H., Quigley, M., Nakiyingi, J., Kyaligonza, S., Namujju, P., Ducar, C., Ellner, J., Whitworth, J., Mugerwa, R., Johnson, J., and Okwera, A. (2004) A randomized, double-blind, placebo-controlled trial of the use of prednisolone as an adjunct to treatment in HIV-1-associated pleural tuberculosis. $J$ Infect Dis. 190, 869-878.

25. Hengge, U., Stocks, K., Wiehler, H., Faulkner, S., Esser, S., Lorenz, C., Jentzen, W., Hengge, D., Goos, M., Dudley, R., and Ringham, G. (2003) Double-blind, randomized, placebo-controlled phase III trial of oxymetholone for the treatment of HIV wasting. AIDS. 17, 699-710.

26. Saunders, J., Wainwright, P. (2003) Risk, Helsinki 2000 and the use of placebo in medical research. Clin Med. 3, 435439.

This article should be referenced as follows:

Al-Waili, N.S., Al-Waili, T.N., Al-Waili, A.N., and Saloom, K.S. (2006). Influence of Natural Honey on Biochemical and Hematological Variables in AIDS: A case study. TSW Holistic Health \& Medicine 1, 21-25. DOI 10.1100/tswhhm.2006.03.

\section{BIOSKETCH}

Noori S Al-Waili, MD, DOG, PhD, CHT, Director of Clinical Research, Life Support technologies INC, Chronic Wound Treatment and Hyperbaric Medicine Center, The Mount Vernon Hospital, Mount Vernon, New York, United States of America. Email: Dr AL-Waili is a physician and research scientist who has gained both in-depth clinical and extensive research experiences in his medical career (20 years). He has been publishing more than 160 scientific publications in nephrology, urology, hypertension, diabetes, malignancy, immunity, alternative medicine and biomedical sciences, including wide range of new therapeutic measures. He has many theories and discoveries in modern and alternative medicine, which have been published in top journals in USA, UK, Australia, Europe and others. He has many exiting publications in nephrology/urology including peritoneal macrophages transfusion, enuresis, renal colic, frequency of micturiton, and others. At time, his main interest is focused on nephrology/urology, wound care and hyperbaric medicine as well as alternative medicine. He is working as a member of Editorial Board of two medical journals, a member of evaluator panel, Current Drug, UK, and a reviewer for many medical and biomedical journals. 


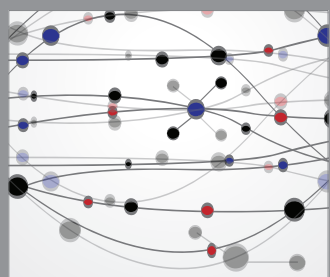

The Scientific World Journal
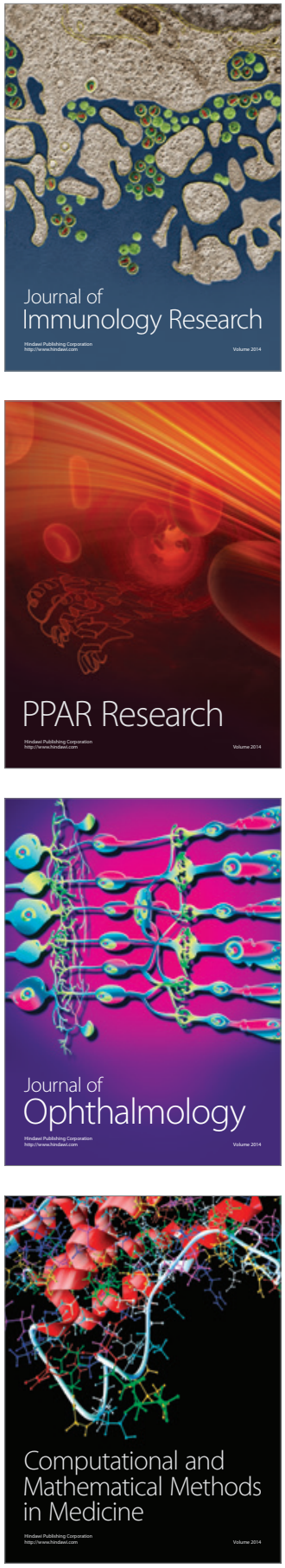

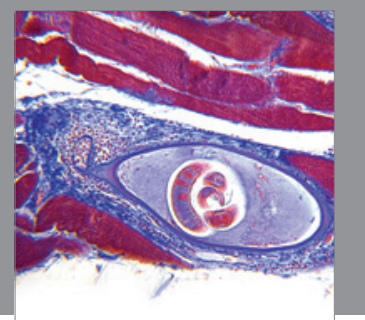

Gastroenterology

Research and Practice
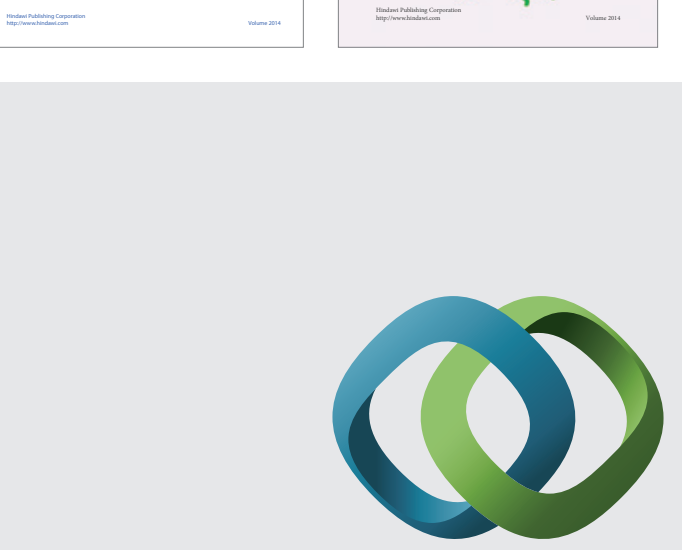

\section{Hindawi}

Submit your manuscripts at

http://www.hindawi.com
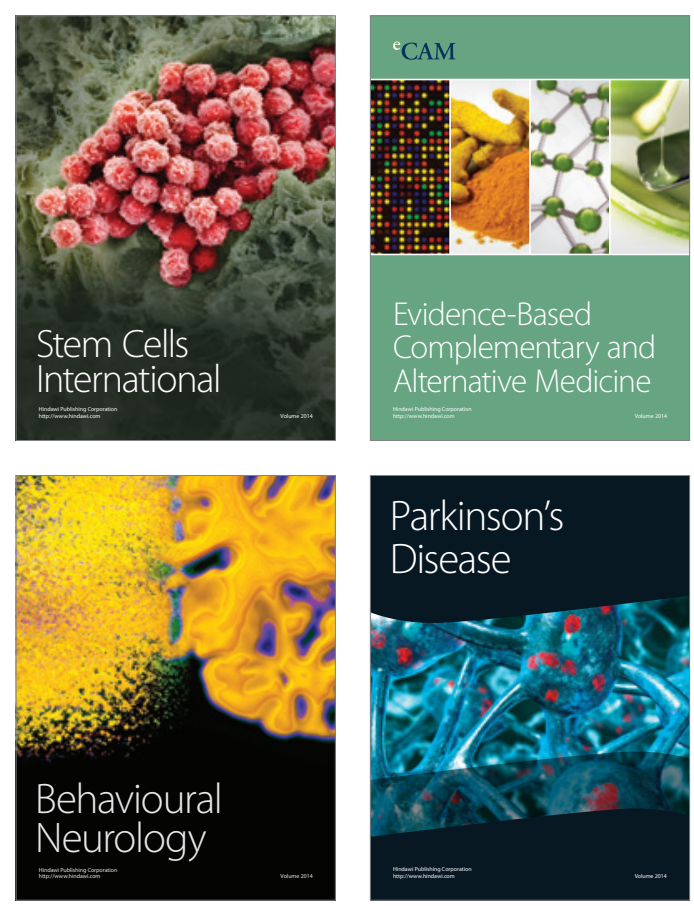

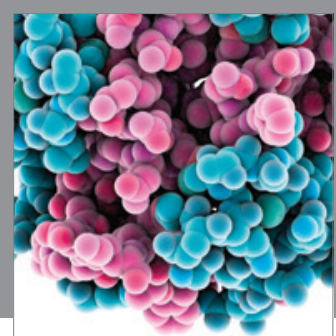

Journal of
Diabetes Research

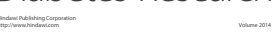

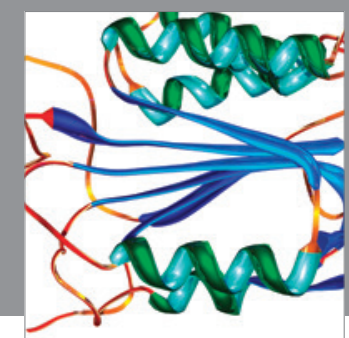

Disease Markers
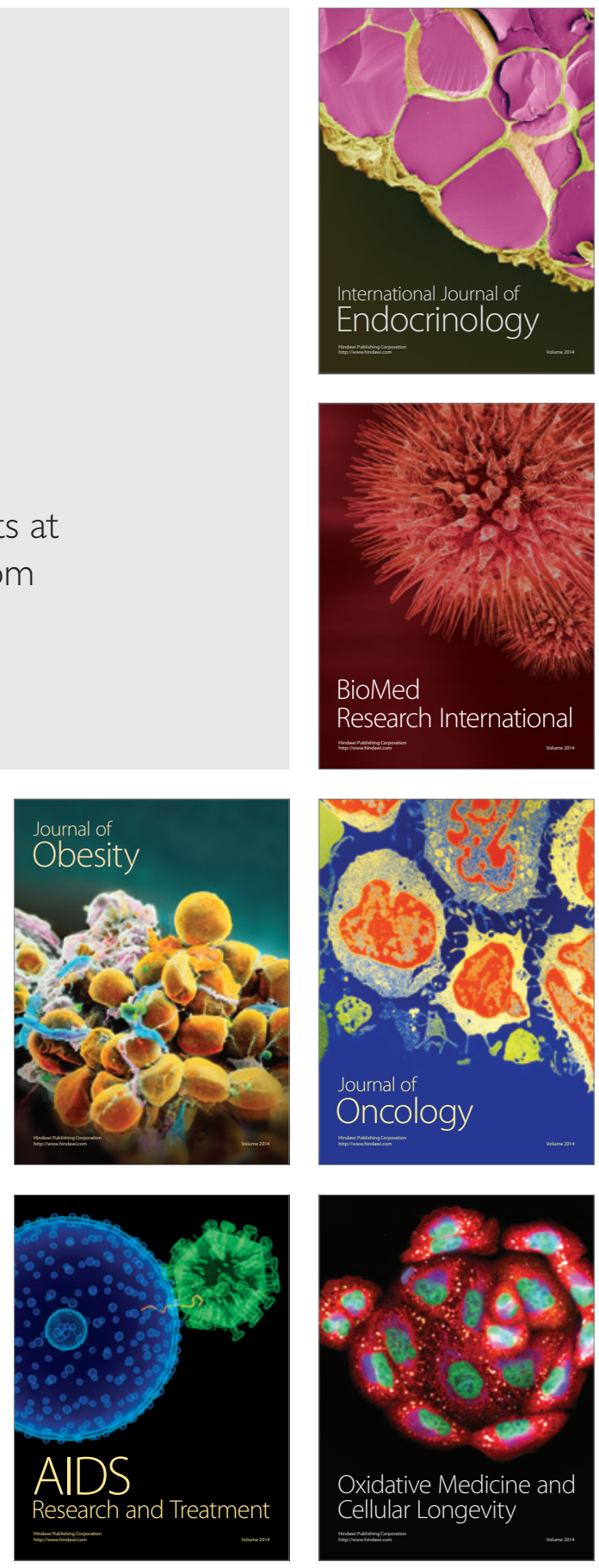